\title{
Notícias do Serviço Educativo do IEB-USP
}

Atuando desde $2006^{1}$, o Serviço Educativo do IEB passa a ser, em 2010, incorporado como Serviço de Apoio tendo como objetivo o desenvolvimento de atividades educativas para a extroversão de seu acervo.

Nas áreas de ensino, pesquisa e extensão, o Serviço Educativo desenvolveu, nesses oito anos, todas as propostas elaboradas em sua implantação que, na medida em que se definia pela demanda atendida, também pode propor novos caminhos para essas ações, muitas delas inéditas em acervos de mesma natureza.

Assim, apresentamos as atividades desenvolvidas e, junto a isso, o agradecimento a todos aqueles que, de alguma forma, colaboraram na construção desta enorme jornada.

\section{Programa oficinas}

\section{Temáticas}

São oficinas cujo conteúdo trata das linguagens existentes nos acervos, bem como a vida dos titulares pertencentes ao Instituto. Abrangem grandes áreas do conhecimento e da produção artística e cultural. Há também, as de temática específica tratando de um movimento ou de uma obra.

1.1. Aspectos de uma biografia: a fotografia como documento

\subsection{Memória e acervos pessoais}

\subsection{Paisagens urbanas}

\subsection{Macunaíma para crianças}

\subsection{Macunaíma para todos}

I Para maiores detalhes ver: FERRARI, Elly Rozo. Implantação do setor de educação do IEB. Revista do Instituto de Estudos Brasileiros, Brasil, n. 47, p. 225-228, set. 2008. ISSN 2316-901X. Disponível em: <http://www.revistas.usp.br/rieb/article/ view/34626/37364>. Acesso em: 29 mai. 2014. DOI: http://dx.doi.org/10.116o6/issn. 2316-9o1X.voi 47 p225-228. 


\section{Expositivas}

São desenvolvidas para as exposições elaboradas pelo IEB, tanto em sua sede no campus como em outros espaços da Universidade e em programa de itinerância na comunidade externa à USP.

\subsection{Os suportes da escrita}

2.2. Blaise Cendars - Escrevendo com Forma

2.3. Paisagem em transformação - o olhar modernista nas artes plásticas

2.4. Paisagem pelo olhar do geógrafo e do escritor

2.5. Paisagem na parede: como pode algo tão parado mudar?

2.6. A Baleia e o criador

2.7. Leituras de Alexandre

2.8. A Turma do Barão

2.9. Anita gravadora: os múltiplos aspectos de uma coleção

\section{Programa de ação educativa avançada}

São oficinas feitas especialmente para os profissionais da educação: professores de educação infantil ( $1^{\mathrm{a}}$ infância inclusive), ensino fundamental, ensino médio, funcionários de todos os níveis que atuam no ambiente escolar.

Tratam de assuntos escolhidos por esses profissionais e desenvolvidos com os acervos do Instituto, sempre contextualizado a partir da vivência e histórico de vida do participante. Visa à produção de sentido da prática, trabalhando questões recorrentes sobre exigência curricular em detrimento da realidade.

1. Arte na educação infantil - módulos I, II e III - ministrada no espaço de formação do DOT Jaçanã/Tremembé.

2. Mediação na Leitura - ministrado no espaço de formação do DOT Jaçanã/Tremembé. 
3. Memória, acervos pessoais e educação - Estágios pedagógicos para licenciaturas:

3.1. Disciplina 4800704 - Atividades em cultura e extensão: práticas formativas I e II - Faculdade de Educação da USP - Ccex;

3.2. Disciplina FLH0421 - Ensino de história: teoria e prática Departamento de História - FFLCH-USP. Prof. ${ }^{a}$ Dr. ${ }^{a}$ Antônia Terra Calazans Fernandes.

4. Orientação pedagógica aos profissionais da educação em seu espaço escolar.

5. Oficinas temáticas no espaço escolar.

6. Orientação pedagógica aos profissionais da educação no espaço do IEB.

7. A arte em diálogo com os(as) educadores(as) das infâncias - no espaço de formação do DOT Jaçanã/Tremembé.

\section{Projetos interdisciplinares}

Educação do olhar: cinema e vídeo como formadores

Projeto inter disciplinar e inter unidades: ECA, FE-USP, IEB, CinUSP - aprovado e publicado pela $w e b$ em 28 de setembro de 2010 - no edital CAPES/DEB n ${ }^{\circ}$ 033/2010. ${ }^{2}$

\section{Seminários e Palestras ministradas pelo SE-IEB}

1. Organização do Seminário Mário, educador: infância e arte - em parceria com a Prof. ${ }^{a}$ Dr. ${ }^{a}$ Márcia Gobbi da Faculdade de Educação da USP - 2010.

2. Educação e exposição: propostas de curadorias educativas $-10^{\circ}$ Encontro de ações educativas e culturais nos espaços expositivos do Grande ABC - Fundação Pró-Memória de São Caetano do Sul 2008.

3. Implantação do Serviço de Educação no Instituto de Estudos

2 Disponível em: <http://www.capes.gov.br/educacao-basica/novos-talentos >. Acesso em: 6 jun. 2014 . 
Brasileiros da USP - Semana de Educação: Identidade e Diversidade FEUSP - 2008.

4. A Baleia e o criador: relato de experiência educuratorial na exposição 'O círculo e as linhas tortas: Vidas Secas de Graciliano Ramos' -VIII SMELP - FEUSP - 2009.

5. Cultura e infância: os desafios da educação infantil - Seminário de Educação Infantil - Encontro de pais e educadores de infância: compartilhando olhares e sonhos - CEU Jaçanã - 2010.

6. A criança pequena nos arquivos de escritores: desafios e práticas da criação - IX SMELP - FEUSP - em parceria com a equipe de coordenadores do CEU Jaçanã - 2010.

7. O colecionismo como construção do desejo - Mesa Redonda: Origem e transferência de acervos pessoais: o papel das bibliotecas na administração dessas coleções - IF-USP - 2011.

8. Exposição de coleção: a relação entre curadoria, pesquisa e extroversão no IEB-USP - $10^{\circ}$ Seminário Acervos de Arquitetura: administração, conservação e difusão - FAU-USP - 2012.

9. Ressignificação da memória: a exposição como construção de sentido de uma coleção - VI Simpósio Nacional de História Cultural - 2012.

10. A importância da exposição de acervos pessoais em instituições de pesquisa. Mesa Arquivos pessoais e Memória - FFLCH - 2012.

11. O reinventar-se da estrela: XVII ANPUH - 2013.

12. As possibilidades de se pensar curadoria hoje - Pinacoteca de São Caetano - 2014.

13. Exposição como conteúdo: a experimentação em espaços expositivos, curadoria e extroversão de acervos pessoais - 2014. 


\section{Itinerância de exposições}

A itinerância é oferecida diretamente pelo Serviço Educativo do IEB. É uma modalidade educativa em que a curadoria e as atividades educativas não são complementares, fazem parte de uma mesma ação.

\section{Caio Prado Jr.}

2. Mário, educador

3. Anita gravadora

\section{Curadoria}

Tratam-se das atividades curatoriais desenvolvidas nas áreas de conceito, expografia e educação para os acervos do IEB.

1. Série Mários:

1.1. As licocós do Mário - 2008

1.2. Mário, [diálogos] - 2010

1.3. Mário, educador - 2010 - 2011

2. As manhas do Barão - 2011.

3. O avesso do avesso: o processo de criação de escritores, artistas plásticos e músicos - Módulo Coleção Lamego, módulo Yan de Almeida Prado, módulo Ernani Silva Bruno e módulo A Exposição na Exposição - Semana de 22 - 2012.

\section{Programas de Cultura e Extensão}

Workshops para o público em geral e/ou grupos representativos ou organizados da comunidade. 
1. USP e as Profissões.

2. USPiTec.

3. Universidade aberta à terceira idade.

\section{Imagens}

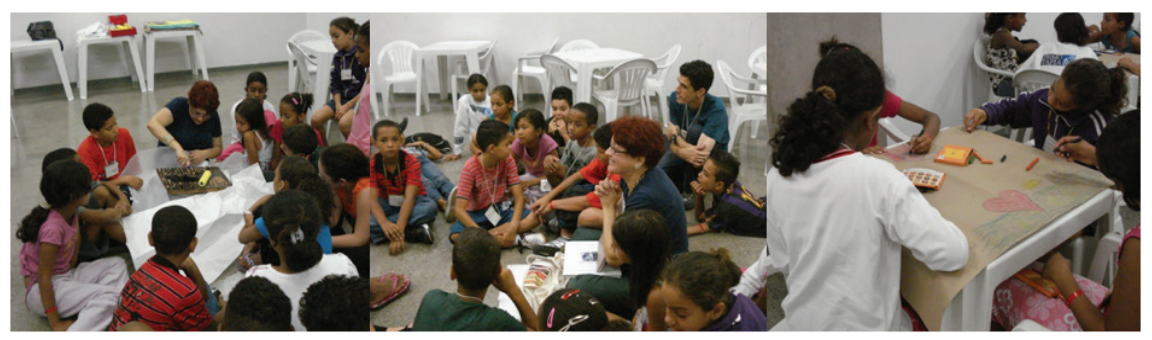

Figura 1: Oficina temática no espaço escolar

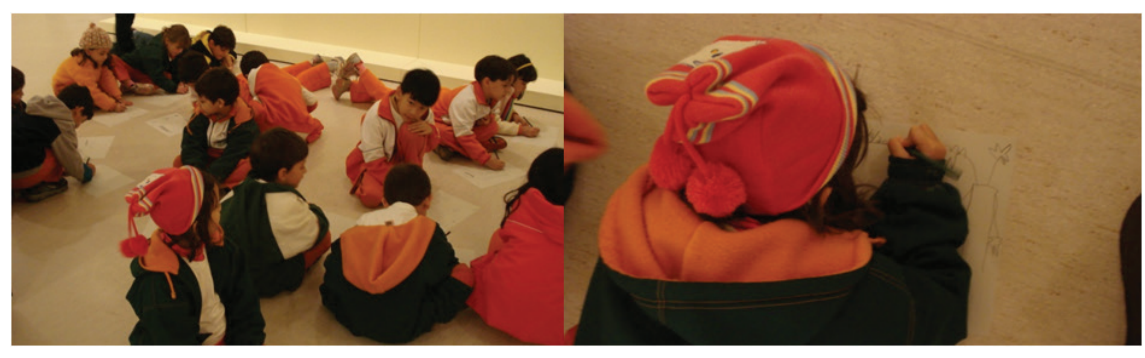

Figura 2: Oficina temática no espaço

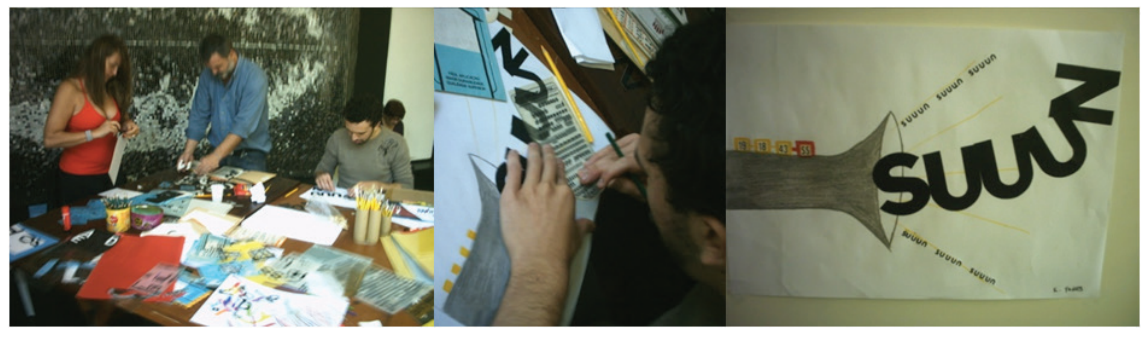

Figura 3: Oficina Blaise Cendars - Escrevendo com Formas 


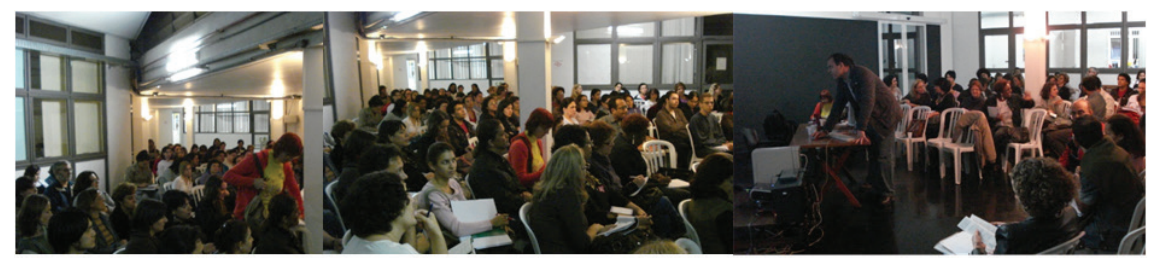

Imagem 4: Seminário Mário, educador: infância e arte

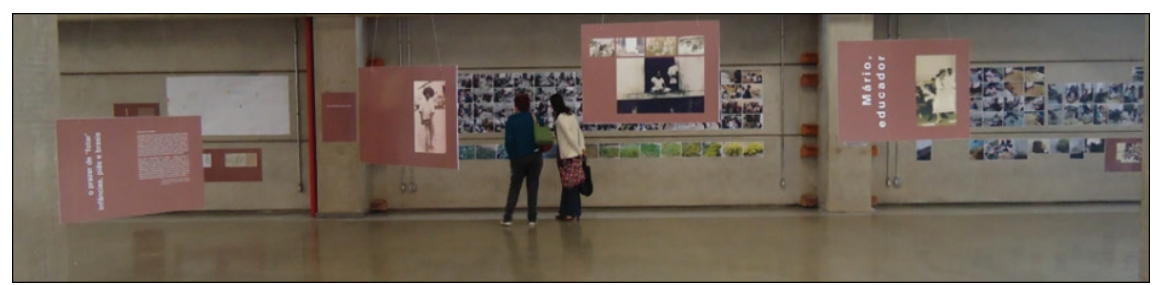

Figura 5: Mário, educador - itinerância

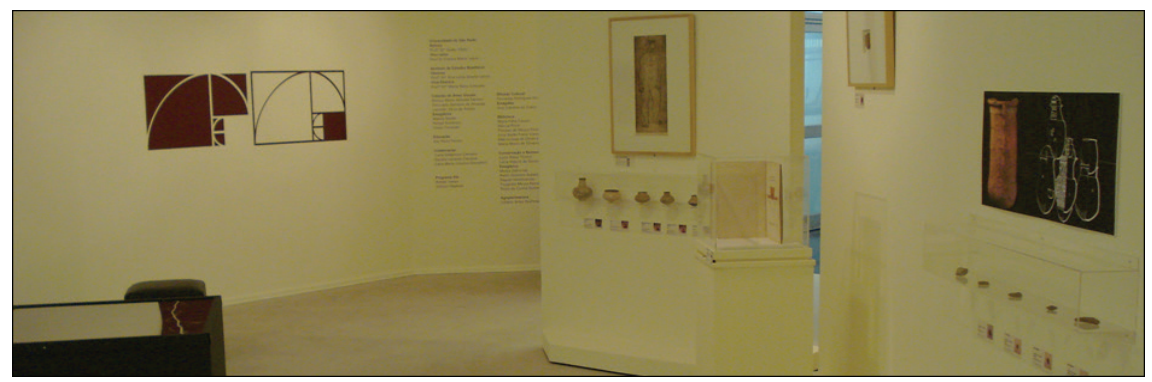

Figura 6: As licocós do Mário

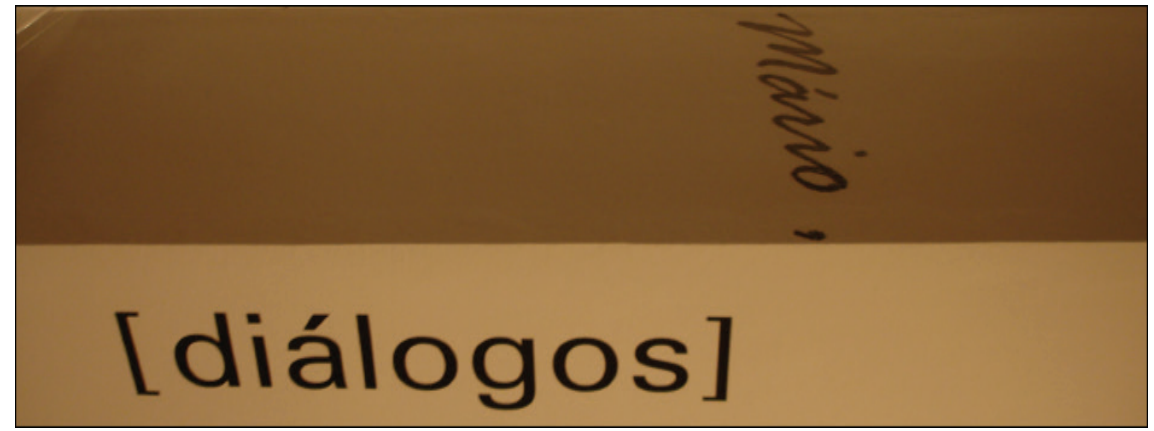

Figura 7: Mário, diálogos. 


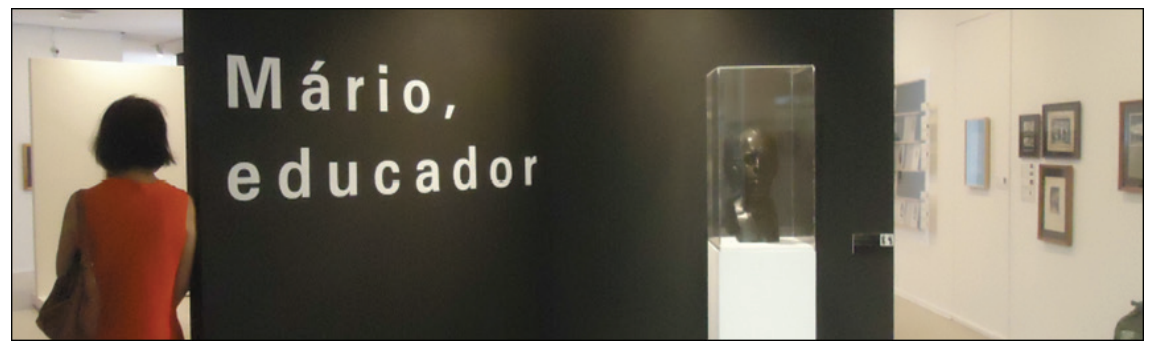

Figura 8: Mário, educador.

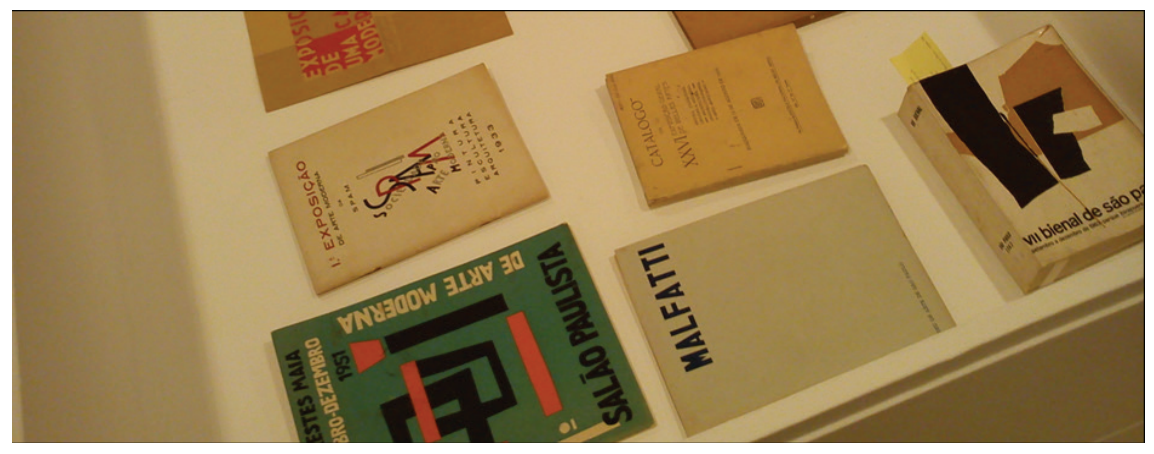

Figura 9: A Exposição na Exposição - O Avesso do Avesso.

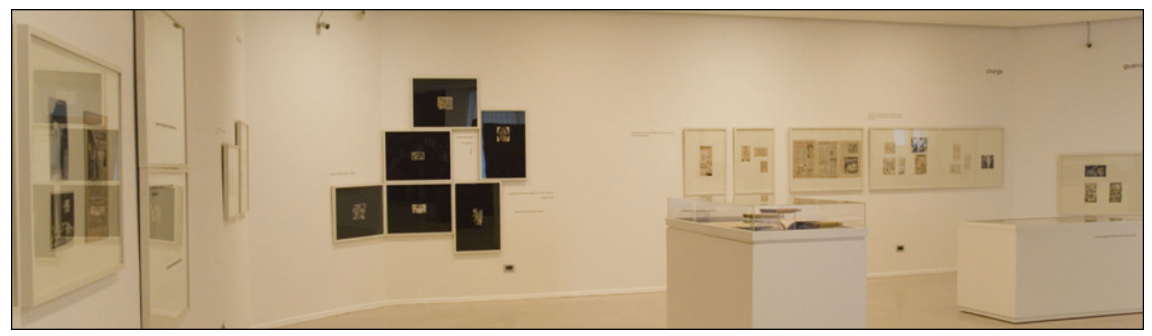

Figura 10: As manhas do Barão.

Elly Rozo Ferrari, Educadora responsável pela implantação e desenvolvimento das atividades do Serviço Educativo do IE 